\title{
TU/e EmonOWEN

\section{A Switched-Mode Power Amplifier for Ion Energy Control In Plasma Etching}

Citation for published version (APA):

Yu, Q., Lemmen, E., Wijnands, C. G. E., \& Vermulst, B. J. D. (2020). A Switched-Mode Power Amplifier for lon Energy Control In Plasma Etching. In 2020 22nd European Conference on Power Electronics and Applications (EPE'20 ECCE Europe) [9215859] Institute of Electrical and Electronics Engineers. https://doi.org/10.23919/EPE20ECCEEurope43536.2020.9215859

DOI:

10.23919/EPE20ECCEEurope43536.2020.9215859

Document status and date:

Published: 01/09/2020

Document Version:

Accepted manuscript including changes made at the peer-review stage

Please check the document version of this publication:

- A submitted manuscript is the version of the article upon submission and before peer-review. There can be important differences between the submitted version and the official published version of record. People interested in the research are advised to contact the author for the final version of the publication, or visit the $\mathrm{DOI}$ to the publisher's website.

- The final author version and the galley proof are versions of the publication after peer review.

- The final published version features the final layout of the paper including the volume, issue and page numbers.

Link to publication

\section{General rights}

Copyright and moral rights for the publications made accessible in the public portal are retained by the authors and/or other copyright owners and it is a condition of accessing publications that users recognise and abide by the legal requirements associated with these rights.

- Users may download and print one copy of any publication from the public portal for the purpose of private study or research.

- You may not further distribute the material or use it for any profit-making activity or commercial gain

- You may freely distribute the URL identifying the publication in the public portal.

If the publication is distributed under the terms of Article 25fa of the Dutch Copyright Act, indicated by the "Taverne" license above, please follow below link for the End User Agreement:

www.tue.nl/taverne

Take down policy

If you believe that this document breaches copyright please contact us at:

openaccess@tue.nl

providing details and we will investigate your claim. 


\title{
A Switched-Mode Power Amplifier for Ion Energy Control In Plasma Etching
}

\author{
Qihao Yu, Erik Lemmen, Korneel Wijnands, Bas Vermulst \\ Department of Electrical Engineering, Eindhoven University of Technology \\ P.O. Box 513, 5600MB \\ Eindhoven, The Netherlands \\ Email: q.yu@tue.nl \\ URL: http://www.tue.nl/epe
}

\section{Acknowledgments}

This research was supported by Prodrive Technologies B.V.. Assistance provided by Javier EscandonLopez and Erik Heijdra was greatly appreciated.

\section{Keywords}

$\ll$ Physics research $\gg, \ll$ Industrial application $\gg, \ll$ Amplifiers $\gg, \ll$ Plasma $\gg$.

\begin{abstract}
Plasma etching is an important process in the semiconductor manufacturing process. In order to precisely control the ion energy for better process quality, a tailored pulse-shape voltage waveform is applied to the plasma reactor table. Traditionally, a linear amplifier is used to generate this waveform, which results in poor efficiency. This paper proposes a switched-mode power amplifier as a substitute to the traditional linear amplifier. The electric equivalent circuit of the plasma reactor is introduced and a basic topology for the switched-mode power amplifier is derived. The basic topology is able to generate the required waveform but it has a low efficiency of charging the capacitive load in practice. Therefore, an efficiencyimproved topology is proposed by adopting resonant charging. A prototype is built in order to validate the research. The experiments show that the presented solution yields a significantly reduced input power compared to the normally used linear amplifier in this application.
\end{abstract}

\section{Introduction}

Plasma consists of positive ions, negative electrons and neutral particles with an approximately neutral net charge [1]. It is widely used in semiconductor manufacturing, such as plasma etching and deposition process. Fig. 1 (a) shows a schematic diagram of a typical setup of an inductively coupled plasma etching chamber. Gas, such as argon or hydrogen, is infused from the top of the chamber. Plasma is ignited and sustained in the chamber by applying an external radio frequency (RF) power supply which is coupled with the gas through a matching network and coils. The pressure in the chamber is kept low by a vacuum pump in order to increase the distance between particles thereby reducing particle collisions. A substrate wafer is placed on the table and the material on the substrate surface is removed by chemical reaction or physical sputtering in a certain pattern, which is called etching. A chemical reactant gas can also be injected into the chamber to react with the surface of the substrate wafer.

An ion sheath is formed where plasma is near the substrate, which is a region where the ion density is larger than the electron density. The fast-moving electrons in plasma easily get lost when confronted with a surface like the substrate, thus leaving excess ions near the surface. As a result, the surface is negatively charged, forming an electric field which attracts ions and repels electrons [2]. By applying a 


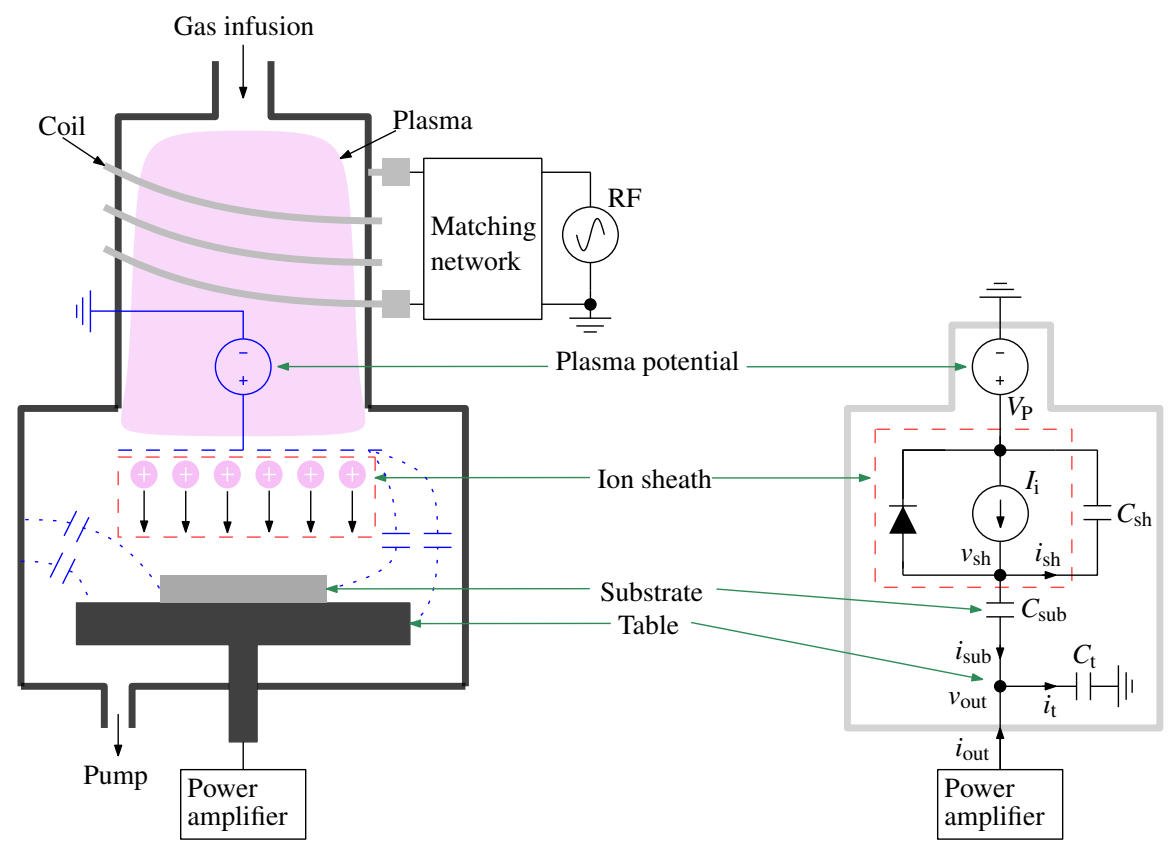

(a)

(b)

Fig. 1: (a) A typical setup of an inductively coupled plasma chamber and (b) its equivalent electric model.

negative voltage to the substrate with a power amplifier connected to the conductive table, the voltage potential of substrate can be controlled. As a result, ions are accelerated by the electric field and bombard the substrate surface. The bombarding ions supply additional energy to the surface and accelerate the chemical reactions. Additionally, the normal direction of ion bombardment to the material surface also enhances the anisotropy of the etching.

For a high-selectivity etching recipe, the ion energy must be within a specific limited range. Ions with too low energy cause a slow reaction rate while ions with too high energy causes sputtering, which decreases the selectivity. With the increasing demands on smaller semiconductor feature size, precise control of ion energy becomes critical in both plasma deposition and etching. In general, a narrow ion energy distribution (IED) falling into a specific energy range is desired.

A narrow IED requires a constant negative voltage potential on the substrate material surface. For a conductive substrate material, a negative dc bias voltage can be directly connected to the table in the plasma chamber. By varying the dc value of the voltage, the energy of the ions can be controlled correspondingly. However, for a dielectric substrate material, there is an equivalent substrate capacitance. An equivalent electric current caused by the bombarding ions is charging the substrate capacitance during etching, resulting in an increasing voltage potential on the substrate surface, thus making the ion energy variant during the process if left uncompensated.

To control the ion energy with a dielectric substrate, different kinds of voltage waveforms have been studied, including the radio-frequency (RF) sinusoidal waveform [3], square waveform [4] and tailored pulse-shape waveform [5], among which the tailored pulse-shape waveform is the most precise one. All of the tailored pulse-shape waveforms in previous researches were generated by class-A linear amplifiers $[5,6,7]$, which are typically expensive and inefficient. In our literature research, no paper or combination of papers was found to consider the power amplifier from the perspective of the power consumption in the physics research. Therefore, in this paper, a power electronics concept based on a switched-mode power amplifier is introduced. It is able to generate the required waveform in order to obtain a narrow IED and at the same time reduce the input power by about $90 \%$ compared to the linear amplifier by improved amplifier efficiency. A prototype was built based on this concept and experiments were conducted on a plasma etching machine for validating the concept. 


\section{Power Electronics Concept}

In order to illustrate the concept, a simplified equivalent electric model is built as depicted in Fig. 1 (b). The bulk plasma is modelled as a voltage source with a positive potential $V_{\mathrm{P}}$ with respect to ground, the magnitude of which is dependent on the temperature and pressure of the chamber and the power of the RF source. $V_{\mathrm{P}}$ is assumed to be constant during etching and is normally tens of volts.

During etching when the substrate potential $v_{\mathrm{sh}}$ is negatively biased, the positive ions are attracted to the substrate. As a result, the bombardment of ions generates an equivalent current $I_{\mathrm{i}}$, which is assumed to be constant in this paper [8]. A sheath capacitance is present between the plasma potential and substrate surface. Besides, there is also a parasitic capacitor between the substrate and the chamber wall [3]. Since the wall is grounded and the plasma potential is constant during the etching phase, they are modelled in total as $C_{\mathrm{sh}} . C_{\mathrm{sh}}$ is variant during etching phase unless the substrate potential is constant.

Depending on the material and composition of the substrate, the substrate can be either dielectric or conductive. For a dielectric substrate, it is modelled as a capacitor $C_{\text {sub }}$. In addition, there are also parasitic capacitances between the table and the chamber wall and between the table and the sheath respectively, which are modelled in total as $C_{\mathrm{t}}$. In practice, both $C_{\text {sub }}$ and $C_{\mathrm{t}}$ are much larger than $C_{\mathrm{sh}}$. As a result, during etching, a series of equations can be used to describe the electric model and given by

$$
\begin{aligned}
& i_{\mathrm{t}}=C_{\mathrm{t}} \frac{\mathrm{d} v_{\text {out }}}{\mathrm{d} t}, \\
& i_{\text {sub }}=C_{\text {sub }}\left(\frac{\mathrm{d} v_{\text {sh }}}{\mathrm{d} t}-\frac{\mathrm{d} v_{\text {out }}}{\mathrm{d} t}\right), \\
& i_{\mathrm{sh}}=C_{\mathrm{sh}} \frac{\mathrm{d} v_{\mathrm{sh}}}{\mathrm{d} t}, \\
& I_{\mathrm{i}}=i_{\mathrm{sh}}+i_{\text {sub }}, \\
& i_{\text {out }}=i_{\mathrm{t}}-i_{\text {sub }} .
\end{aligned}
$$

In order to obtain a narrow ion energy distribution, a constant $v_{\mathrm{sh}}$ is desired thus $\frac{\mathrm{d} v_{\mathrm{sh}}}{\mathrm{d} t}=0$. By further manipulating the above equations, the required characteristics of the power amplifier can be derived and are governed by

$$
\begin{aligned}
& \frac{\mathrm{d} v_{\text {out }}}{\mathrm{d} t}=-\frac{I_{\mathrm{i}}}{C_{\text {sub }}}, \\
& i_{\text {out }}=-I_{\mathrm{i}}-\frac{I_{\mathrm{i}} C_{\mathrm{t}}}{C_{\text {sub }}} .
\end{aligned}
$$

Therefore, the output voltage $v_{\text {out }}$ of the amplifier is a negative voltage ramp and the output current $i_{\text {out }}$ of the amplifier is a negative constant current in etching process.

However, since $C_{\text {sub }}$ is continuously charging during etching, it is required to discharge it periodically to avoid over-voltage on substrate. A short positive voltage pulse can be used to discharge the substrate. During discharge, the voltage potential of the substrate surface is reset to a positive value by the discharge voltage. The fast-moving electrons are then attracted to the substrate surface rapidly so as to compensate the excess ions accumulated on the substrate surface, after which a negative voltage pulse should be applied to the table to restart the etching process. It should be noted that the equivalent electric model is only applicable to the etching phase. The discharge phase is rather complex and lasts for only a very short moment, moreover it is not the main focus of this paper.

The typical waveforms of $v_{\text {out }}, v_{\mathrm{sh}}, v_{C_{\text {sub }}}$ and $i_{\text {out }}$ are shown in Fig. 2, among which the waveform of $v_{\text {out }}$ is the so-called tailored pulse-shape voltage waveform. The waveform is divided into a discharge phase and an etching phase with a duration of $T_{\text {dis }}$ and $T_{\text {pro }}$ respectively. $V_{\mathrm{d}}, V_{\mathrm{s}}$ and $V_{\mathrm{e}}$ are the discharge voltage, start and end voltage of the etching respectively. The ion energy is controlled by varying $V_{\mathrm{s}}$ and it is approximately equal to $e\left(V_{\mathrm{P}}+V_{\mathrm{s}}\right)$, where $e$ is the element charge. 

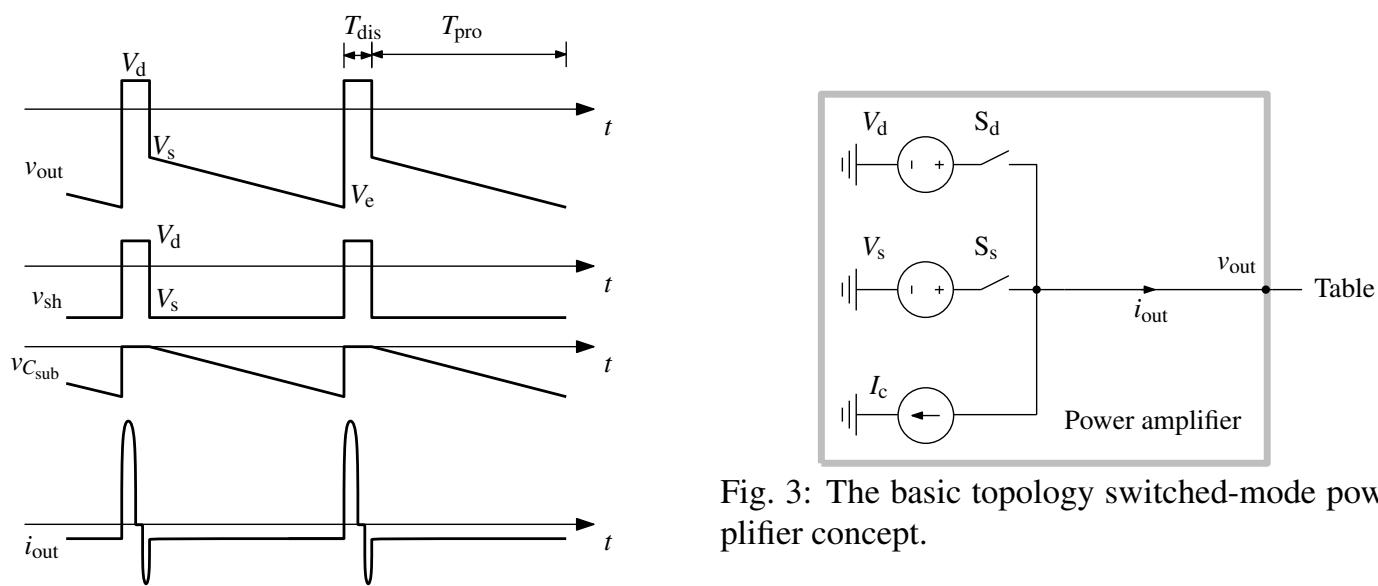

Fig. 3: The basic topology switched-mode power amplifier concept.

Fig. 2: The typical waveforms of $v_{\text {out }}, v_{\mathrm{sh}}, v_{C_{\text {sub }}}$ and $i_{\text {out }}$.

At the beginning of the discharge and etching phase, the voltage of $C_{\mathrm{t}}$ should be charged promptly to $V_{\mathrm{d}}$ and $V_{\mathrm{s}}$ respectively. During the etching phase, there are two possibilities for generating a narrow IED: using a voltage source with a negative voltage ramp output or using a dc current source with a constant negative current output. The dc current source has the benefit of lower bandwidth requirement. Therefore, a basic switched-mode power amplifier concept is derived, which consists of two dc voltage sources and one dc current source, as shown in Fig. 3. By turning on $S_{\mathrm{d}}, V_{\mathrm{d}}$ is connected to the table and the discharge phase starts. Similarly, by turning off $S_{\mathrm{d}}$ and turning on $S_{\mathrm{s}}$, it turns to the etching phase. By turning off both $S_{\mathrm{d}}$ and $S_{\mathrm{s}}$, etching starts properly.

\section{Topology}

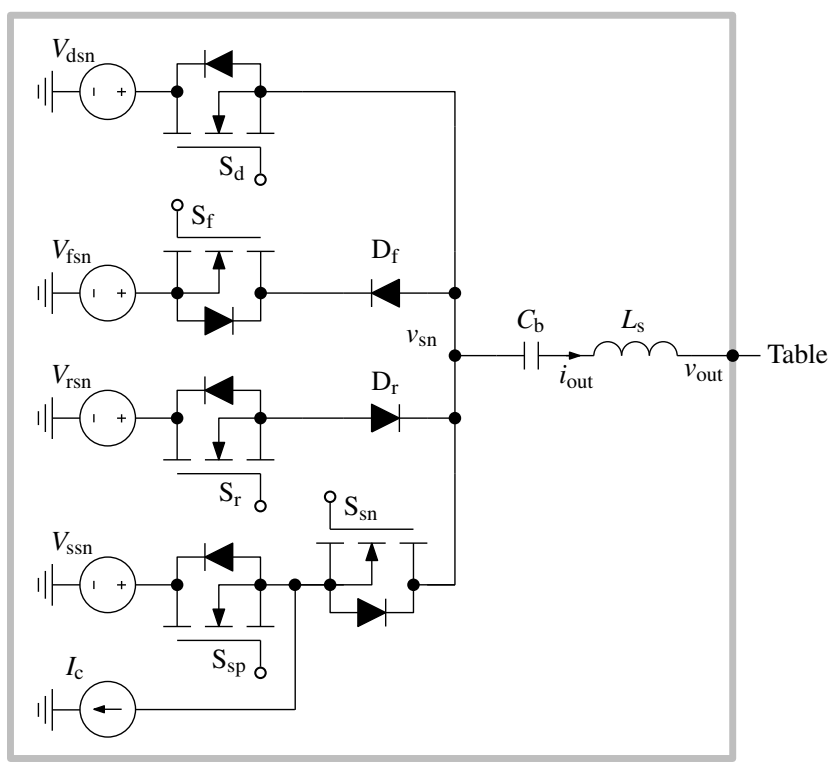

Fig. 4: The topology of the switched-mode power amplifier.

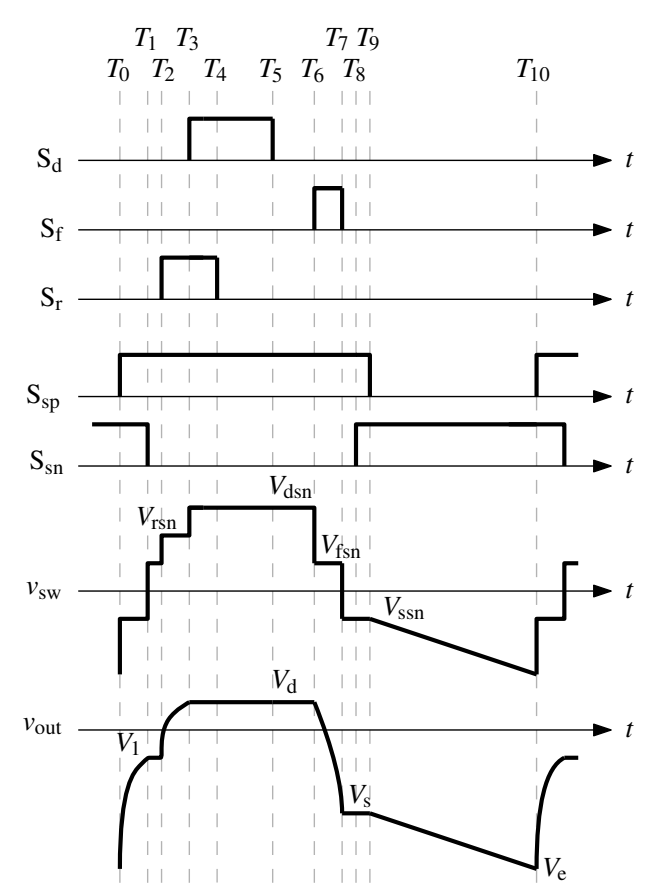

Fig. 5: The operation of the switched-mode power amplifier.

The basic topology shown in Fig. 3 illustrates a concept of generating the bias waveform by power electronics solution. As shown in Fig. 1, the load of the amplifier is capacitive and the equivalent capacitance $C_{\text {eq }}$ is given by

$$
C_{\mathrm{eq}}=C_{\mathrm{t}}+\frac{C_{\mathrm{sub}}+C_{\mathrm{sh}}}{C_{\mathrm{sub}} C_{\mathrm{sh}}} .
$$

However, charging and discharging a capacitor by directly connecting it to a voltage source leads to only 
a maximum $50 \%$ power efficiency. In order to reduce the power loss, resonant charging can be adopted by adding an inductor between the voltage source and the load $[9,10]$.

The power amplifier depicted in Fig. 4 shows one feasible topology, which is able to charge and discharge the capacitive load softly thus significantly reducing the power loss. The amplifier consists of four controllable dc voltage levels $V_{\mathrm{dsn}}, V_{\mathrm{fsn}}, V_{\mathrm{rsn}}$ and $V_{\mathrm{ssn}}$ and one controllable dc current source $I_{\mathrm{c}}$. $V_{\mathrm{dsn}}$ and $V_{\text {ssn }}$ are utilized to generate $V_{\mathrm{d}}$ and $V_{\mathrm{s}}$ at the output respectively. $V_{\mathrm{fsn}}$ and $V_{\mathrm{rsn}}$ are two intermediate voltage levels used to reduce the resonance. The dc current source can be realized by an inductor in series with a voltage source. $L_{\mathrm{S}}$ is the resonant inductor and it can be the stray inductance of the chamber and connection. A blocking capacitor $C_{\mathrm{b}}$ is used at the switch-node in order to produce an equal current flowing into both side of the amplifier [11]. A self-biasing dc offset voltage $V_{\mathrm{b}}$ is then formed over $C_{\mathrm{b}}$, the value of which is determined by the plasma condition and the output waveform. Normally, the value of $C_{\mathrm{b}}$ should be much larger than $C_{\mathrm{t}}$ and $C_{\text {sub }}$ so that $V_{\mathrm{b}}$ can be assumed constant during steady state operation. In this case, $V_{\mathrm{dsn}}, V_{\mathrm{r}}$ and $V_{\mathrm{ssn}}$ are governed by

$$
\begin{aligned}
& V_{\mathrm{dsn}}=V_{\mathrm{d}}+V_{\mathrm{b}}, \\
& V_{\mathrm{r}}=V_{\mathrm{r}}+V_{\mathrm{b}}, \\
& V_{\mathrm{ssn}}=V_{\mathrm{s}}+V_{\mathrm{b}} .
\end{aligned}
$$

The operation of the power amplifier is depicted in Fig. 5. The time of a complete cycle is $T_{10}-T_{0}$. The details of the operation is explained as follows.

- $T_{0}$ : at the end of the etching phase, $S_{\mathrm{d}}$ is turned on. The current $I_{\mathrm{c}}$ is connected in series with the voltage source $V_{\mathrm{ssn}}$. At the same time, the switch-node voltage $v_{\mathrm{sw}}=V_{\mathrm{ssn}}$. The resonance between $L_{\mathrm{s}}$ and $C_{\text {eq }}$ is then triggered. Since the resistance in the loop is small and can be neglected, the output voltage can be described by

$$
v_{\text {out }}(t)=V_{\mathrm{e}}+\left(V_{\mathrm{s}}-V_{\mathrm{e}}\right)\left[1-\cos \left(\omega_{\mathrm{r}}\left(t-T_{0}\right)\right)\right],
$$

where $\omega_{\mathrm{r}}$ is the resonant frequency and determined by $\omega_{\mathrm{r}}=\frac{1}{\sqrt{L_{\mathrm{s}} C_{\mathrm{eq}}}}$. The output current is given by

$$
i_{\text {out }}(t)=\frac{V_{\mathrm{s}}-V_{\mathrm{e}}}{\omega_{\mathrm{o}} L} \sin \left(\omega_{\mathrm{r}}\left(t-T_{0}\right)\right)-I_{\mathrm{c}} .
$$

$I_{\mathrm{c}}$ is typically much smaller than the magnitude of the current resonance thus it can be neglected.

- $T_{1}: \mathrm{S}_{\mathrm{sn}}$ is turned off and the current source $I_{\mathrm{c}}$ is disconnected from the switch-node. In order to minimize the resonance, the energy stored in $L_{\mathrm{S}}$ should be fully discharged, which leads to

$$
i_{\text {out }}\left(T_{1}\right) \simeq \frac{V_{\mathrm{s}}-V_{\mathrm{e}}}{\omega_{\mathrm{o}} L} \sin \left(\omega_{\mathrm{r}}\left(T_{1}-T_{0}\right)\right)=0 .
$$

Therefore, $T_{1}=T_{0}+\frac{1}{2} T_{\mathrm{r}}$, where $T_{\mathrm{r}}=\frac{2 \pi}{\omega_{\mathrm{r}}}$. In this time interval, $v_{\text {out }}=2 V_{\mathrm{s}}-V_{\mathrm{e}}$ and $i_{\mathrm{L}} \simeq 0$.

- $T_{2}$ : $\mathrm{S}_{\mathrm{r}}$ is turned on after $\mathrm{S}_{\mathrm{sn}}$ is turned off. The switch-node voltage $v_{\mathrm{sw}}$ is equal to the intermediate voltage $V_{\text {rsn }}$. In order to prevent short circuit, $T_{2}-T_{1}$ should be larger than the dead-time of the MOSFET. Similar to $T_{0}$, the resonance is triggered again and the output voltage is given by

$$
v_{\text {out }}(t)=2 V_{\mathrm{s}}-V_{\mathrm{e}}+\left(V_{\mathrm{r}}-2 V_{\mathrm{s}}+V_{\mathrm{e}}\right)\left[1-\cos \left(\omega_{\mathrm{r}}\left(t-T_{2}\right)\right)\right] .
$$

- $T_{3}: \mathrm{S}_{\mathrm{d}}$ is turned on. Similar to $T_{1}$, in order to minimize the resonance, $T_{3}$ should be equal to $T_{3}=T_{2}+\frac{1}{2} T_{\mathrm{r}}$. In this time interval, $v_{\text {out }}=2 V_{\mathrm{r}}-2 V_{\mathrm{s}}+V_{\mathrm{e}}$ and $i_{\mathrm{L}} \simeq 0$. Since $v_{\text {out }}$ should be equal to $V_{\mathrm{d}}, V_{\mathrm{r}}$ is then given by

$$
V_{\mathrm{r}}=V_{\mathrm{s}}+\frac{1}{2}\left(V_{\mathrm{d}}-V_{\mathrm{e}}\right) .
$$

- $T_{4}: \mathrm{S}_{\mathrm{r}}$ is turned off after $\mathrm{S}_{\mathrm{d}}$ is turned on. The output voltage remains $V_{\mathrm{d}}$. 
- $T_{5}: \mathrm{S}_{\mathrm{d}}$ is turned off. The output voltage remains $V_{\mathrm{d}}$.

- $T_{6}: \mathrm{S}_{\mathrm{f}}$ is turned on after $\mathrm{S}_{\mathrm{d}}$ is turned off. The switch-node voltage $v_{\mathrm{sw}}$ is equal to the intermediate voltage $V_{\mathrm{fsn}}$. In order to prevent short circuit, $T_{6}-T_{5}$ should be larger than the dead-time of the MOSFET. The resonance is triggered and the output voltage is given by

$$
v_{\text {out }}(t)=V_{\mathrm{d}}+\left(V_{\mathrm{f}}-V_{\mathrm{d}}\right)\left[1-\cos \left(\omega_{\mathrm{r}}\left(t-T_{6}\right)\right)\right] .
$$

- $T_{7}: \mathrm{S}_{\mathrm{f}}$ is turned off and the etching phase is started. The resonance is minimized if $T_{7}=T_{6}+\frac{1}{2} T_{\mathrm{r}}$. The output voltage in this interval is given by $v_{\text {out }}=2 V_{\mathrm{f}}-V_{\mathrm{d}}$. Since $v_{\text {out }}$ should be equal to $V_{\mathrm{s}}, V_{\mathrm{f}}$ is then governed by

$$
V_{\mathrm{f}}=\frac{1}{2}\left(V_{\mathrm{s}}+V_{\mathrm{d}}\right) .
$$

- $T_{8}: \mathrm{S}_{\mathrm{sn}}$ is turned on after $\mathrm{S}_{\mathrm{f}}$ is turned off. The current source $I_{\mathrm{c}}$ is connected to the switch-node and ready to sink current from the load. In order to prevent short circuit, $T_{8}-T_{7}$ should be larger than the dead-time of the MOSFET. The output voltage remains $V_{\mathrm{s}}$.

- $T_{9}: \mathrm{S}_{\mathrm{sp}}$ is turned off after $\mathrm{S}_{\mathrm{sn}}$ is turned on. All the voltage source are disconnected. The output voltage is decreasing linearly due to the the current source $I_{c}$. The slope rate of the output voltage is determined by

$$
\frac{\mathrm{d} v_{\mathrm{out}}}{\mathrm{d} t}=\frac{I_{\mathrm{i}} C_{\mathrm{sub}}-I_{\mathrm{c}}\left(C_{\mathrm{sub}}+C_{\mathrm{sh}}\right)}{C_{\mathrm{sh}} C_{\mathrm{sub}}+C_{\mathrm{t}} C_{\mathrm{sh}}+C_{\mathrm{t}} C_{\mathrm{sub}}}
$$

- $T_{10}$ : the etching phase is ended. The end voltage $V_{\mathrm{e}}$ is approximated by

$$
V_{\mathrm{e}}=\frac{I_{\mathrm{i}} C_{\mathrm{sub}}-I_{\mathrm{c}}\left(C_{\mathrm{sub}}+C_{\mathrm{sh}}\right)}{C_{\mathrm{sh}} C_{\mathrm{sub}}+C_{\mathrm{t}} C_{\mathrm{sh}}+C_{\mathrm{t}} C_{\mathrm{sub}}} T_{\mathrm{pro}}+V_{\mathrm{s}}
$$

where $T_{\text {pro }} \simeq T_{10}-T_{7}$.

\section{Experimental validation}

A prototype was built based on the introduced topology to validate the analysis. Experiments were conducted by testing the prototype in an Oxford Instruments FlexAL 2 plasma reactor, which is an atomic layer etching /deposition (ALE/D) machine, as shown in Fig. 6. The original integrated linear amplifier is uninstalled and the designed power amplifier is connected to the table instead. Argon plasma is excited and sustained with an RF power of $600 \mathrm{~W}$ and the constant pressure of the chamber is of 2.2 mTorr. A dielectric wafer is used as a substrate. It is hard to measure $v_{\mathrm{sh}}$ during the process inside the chamber but the ion energy distribution is measured by a retarding-field energy analyser (RFEA), as shown in Fig. 7.

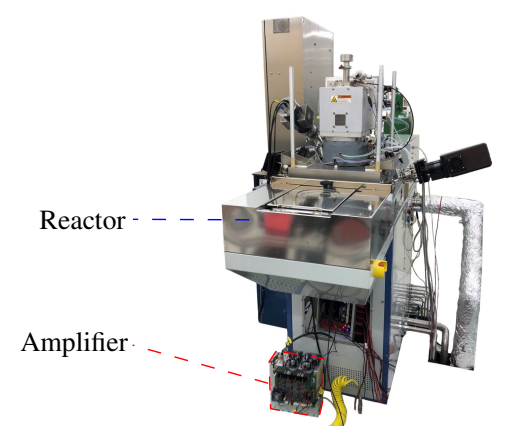

Fig. 6: The FlexAL 2 ALE/D machine.

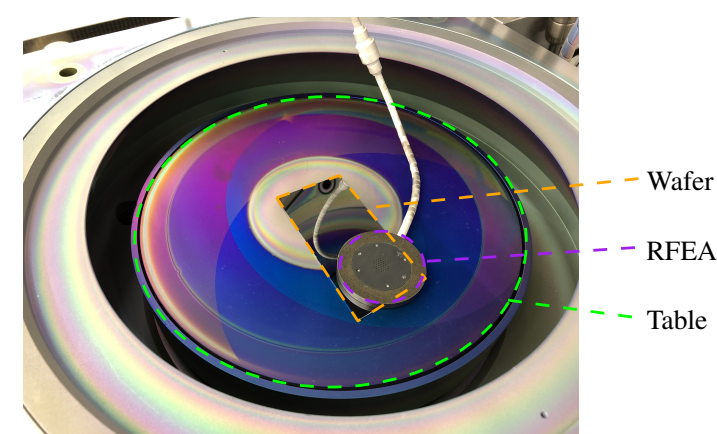

Fig. 7: The reactor table, wafer and RFEA.

The waveforms of $v_{\text {out }}$ and $i_{\text {out }}$ are measured with high-bandwidth differential voltage probe and current probe respectively and shown in Fig. $8 . V_{\mathrm{d}}$ is about $30 \mathrm{~V}$ and $V_{\mathrm{s}}$ is about $-190 \mathrm{~V}$. Constant $I_{\mathrm{c}}$ is measured to be about $15 \mathrm{~mA}$. The repetition rate is $100 \mathrm{kHz}$ and duty cycle of etching is $90 \%$, resulting in $V_{\mathrm{e}}=-228 \mathrm{~V}$. The measured normalized ion energy distribution is shown in Fig. 9. It can be seen that 
the ion energy is mainly distributed around $232 \mathrm{eV}$, which is basically consistent with $V_{\mathrm{s}}$. The plasma potential during etching can then be calculated by $V_{\mathrm{P}}=232-190=42 \mathrm{~V}$. The input power supplying to the power amplifier is only about $20 \mathrm{~W}$. Compared to the linear amplifier used under the same condition [3] with a $200 \mathrm{~W}$ input power, a reduction of the input power of more than $90 \%$ is achieved while a narrow and single-peaked IED is obtained.

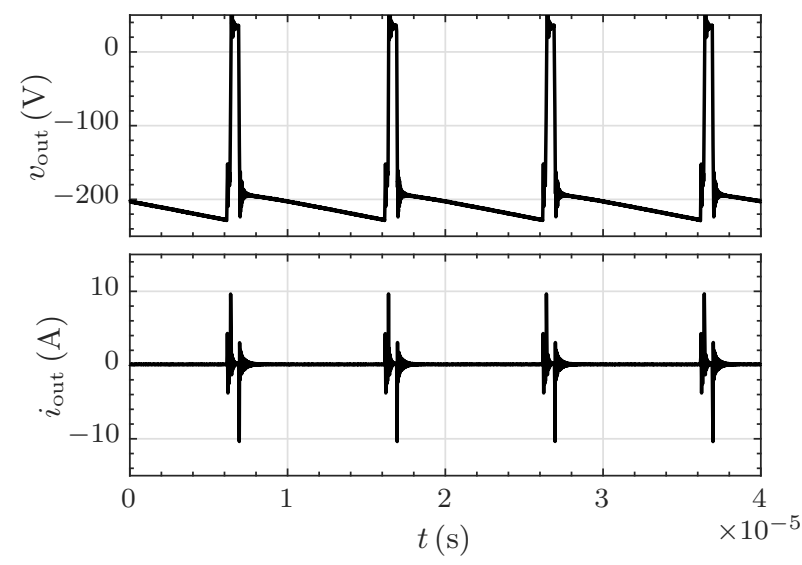

Fig. 8: The measured waveforms of $v_{\text {out }}$ and $i_{\text {out }}$.

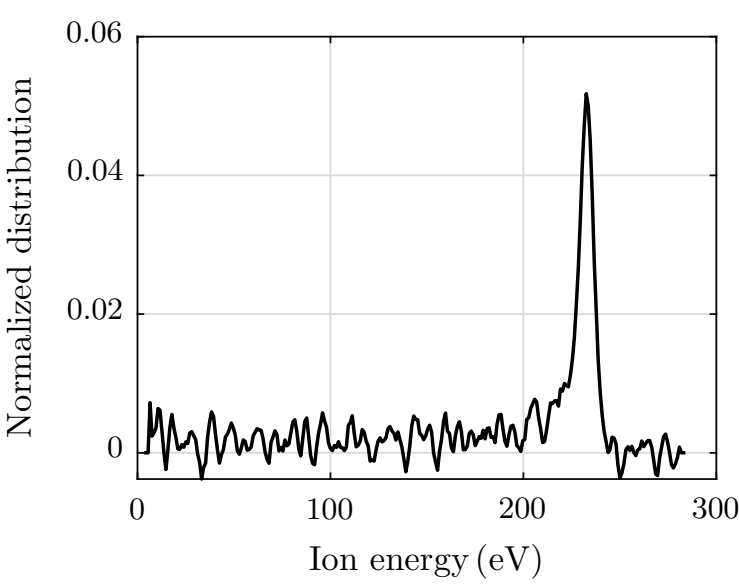

Fig. 9: The measured ion energy distribution.

\section{Conclusion}

Plasma etching requires a narrow ion energy distribution to improve the etching quality. In order to obtain precise ion energy control, a tailored pulse-shape voltage waveform generator is used for biasing the substrate. Typically a class-A linear amplifier is used, which is inefficient and expensive. In this paper, an electric equivalent model of the plasma chamber during etching is introduced and described analytically, based on which a switched-mode power amplifier concept is derived. Furthermore, an efficiency-improved topology is proposed by adopting resonant charging. The topology consists of four switched dc voltage sources and a dc current source. Two of the intermediate voltage sources are utilized during rise and fall transient of the voltage pulse in order to minimized the resonance.

A prototype amplifier is built and tested on a plasma etching machine. The measured ion energy yields a very narrow distribution while the input power of the prototype is reduced by more than $90 \%$ compared to that of a linear amplifier used in previous research, underlining the effectiveness of the concept. The paper shows a significant potential and prospect of bringing power electronics to the plasma physics application.

\section{References}

[1] M. A. Lieberman and A. J. Lichtenberg, Principle of plasma discharges and materials processing, 2 nd ed. John Wiley \& Sons, Inc., 2005, no. 1.

[2] D. J. Economou, "Tailored ion energy distributions on plasma electrodes," J. Vac. Sci. Technol. A Vacuum, Surfaces, Film., vol. 31, no. 5, p. 050823, 2013.

[3] H. B. Profijt, M. C. M. van de Sanden, and W. M. M. Kessels, "Substrate-biasing during plasma-assisted atomic layer deposition to tailor metal-oxide thin film growth," J. Vac. Sci. Technol. A Vacuum, Surfaces, Film., vol. 31, no. 1, p. 01A106, jan 2013.

[4] S. Rauf, "Effect of bias voltage waveform on ion energy distribution," J. Appl. Phys., vol. 87, no. 11, pp. 7647-7651, 2000.

[5] P. Kudlacek, R. F. Rumphorst, and M. C. M. van de Sanden, "Accurate control of ion bombardment in remote plasmas using pulse-shaped biasing," J. Appl. Phys., vol. 106, no. 7, p. 073303, oct 2009.

[6] S.-B. Wang and A. E. Wendt, "Control of ion energy distribution at substrates during plasma processing," $J$. Appl. Phys., vol. 88, no. 2, pp. 643-646, jul 2000.

[7] I. T. Martin, M. A. Wank, M. A. Blauw, R. A. C. M. M. van Swaaij, W. M. M. Kessels, and M. C. M. van de Sanden, "The effect of low frequency pulse-shaped substrate bias on the remote plasma deposition of a-Si : H thin films," Plasma Sources Sci. Technol., vol. 19, no. 1, p. 015012, jan 2010.

[8] F. F. Chen and J. P. Chang, Lecture Notes on Principles of Plasma Processing. Boston, MA: Springer US, 2003. 
[9] Y. P. B. Yeung, K. W. E. Cheng, S. L. Ho, K. K. Law, and D. Sutanto, "Unified analysis of switched-capacitor resonant converters," IEEE Trans. Ind. Electron., vol. 51, no. 4, pp. 864-873, 2004.

[10] A. Cervera, M. Evzelman, M. M. Peretz, and S. S. Ben-Yaakov, "A high-efficiency resonant switched capacitor converter with continuous conversion ratio," IEEE Trans. Power Electron., vol. 30, no. 3, pp. 1373-1382, 2015.

[11] S.-H. Song and M. J. Kushner, "Role of the blocking capacitor in control of ion energy distributions in pulsed capacitively coupled plasmas sustained in Ar/CF4/O2," J. Vac. Sci. Technol. A Vacuum, Surfaces, Film., vol. 32, no. 2, p. 021306, mar 2014. 